\section{P1-484 SOCI0-CULTURAL BELIEFS AND SEXUAL ACTIVITY AMONG POST-MENOPAUSAL WOMEN IN IBADAN NORTHEAST LOCAL GOVERNMENT AREA, NIGERIA}

doi:10.1136/jech.2011.142976g.73

0 Omobowale, * M Onadeko, E Owoaje. University College Hospital, Ibadan Oyo State, Nigeria

Little or no work has been done on sociocultural beliefs and sexual activity of postmenopausal women in Nigeria. This study was carried out to assess socio-cultural beliefs and sexual activity among postmenopausal women in Ibadan NorthEast Local Government Area. A cross-sectional study was conducted among 522 postmenopausal women aged 40-65 years. An interviewer-administered questionnaire was used to collect data on sociodemographic characteristics, attitude to sociocultural beliefs regarding sexual activity and current sexual activity of respondents. Descriptive $\chi^{2}$ and logistic regression were used for data analysis. The mean age of the respondents was $54.0 \pm 5.6$ years. Overall, $45.7 \%$ agreed with at least one of the stated socio-cultural beliefs and the mean attitudinal score was $4.1 \pm 3.2$. Among those who currently had partners, only $30.7 \%$ reported post-menopausal sexual activity. Significantly higher proportions of those with no formal education (78.6\%), those aged $\geq 50$ years $(69.9 \%)$ and with supportive attitude towards the sociocultural beliefs (83.8\%) reported cessation of post-menopausal sexual activity $(p<0.05)$. The significant predictors for cessation of post-menopausal sexual activity were no formal education $(\mathrm{OR}=4.1,95 \% \mathrm{CI}$ from 2.0 to 8.3 ), supportive attitude towards socio-cultural beliefs ( $\mathrm{OR}=5.6,95 \% \mathrm{CI}$ from 3.4 to 9.4 ) and older age group ( $\mathrm{OR}=4.1,95 \% \mathrm{CI}$ from 2.4 to 7.0 ). Socio-cultural beliefs affected post-menopausal sexual activity among these women; this may result in their partners seeking for alternative sexual partners with the attendant problems of sexually transmitted infections. There is need for the development of educational interventions targeted at changing these beliefs.

\section{P1-485 EXPANDING BETWEEN-SCHOOL DIFFERENCES IN SMOKING PREVALENCE OF HIGH SCHOOL STUDENTS IN JAPAN}

doi:10.1136/jech.2011.142976g.74

${ }^{1} \mathrm{Y}$ Osaki, ${ }^{2} \mathrm{~T}$ Ohida, ${ }^{3} \mathrm{H}$ Kanda, ${ }^{1} \mathrm{~T}$ Kishimoto, ${ }^{4} \mathrm{~T}$ Tanihata, ${ }^{2} \mathrm{Y}$ Kaneita. ${ }^{1}$ Tottori University, Faculty of Medicine, Yonago, Tottori, Japan; ${ }^{2}$ Nihon University, Itabashi, Tokyo, Japan; ${ }^{3}$ Fukushima Medical University, Fukushima, Fukushima, Japan; ${ }^{4}$ National Institute of Public Health, Wako, Saitama, Japan

Purpose Trends in school-based differences of smoking prevalence among high school students in Japan was analysed to assess social inequalities in health among adolescents.

Methods Cross-sectional nationwide surveys were conducted periodically. High schools were randomly sampled from throughout Japan in 1996, 2000, 2004, and 2008. All enrolled students in sampled schools were asked smoking and drinking behaviour. The number of schools participated in the survey was 80 junior high schools and 73 senior high schools in 1996 survey. The values were 99 and 77 in 2000, 92 and 87 in 2004, and 92 and 80 in 2008 survey, respectively. For assessing the differences in prevalence, the coefficient of variation (CV) was used.

Results Smoking prevalence among students has decreased for both sexes. According to the lowering smoking prevalence, the variance of between-school differences in smoking prevalence has shrunk, however CV of the experiment rate, current smoking (smoked at least 1 day of the 30 days preceding the survey), and daily smoking has increased for both sexes and both junior and senior high school. For example, CV of current smoking in junior high school boys was
0.51 in 1996, 0.52 in 2000, 0.66 in 2004, and 0.92 in 2008. The CV in junior high school girls was 0.62 in 1996, 0.63 in 2000, 0.93 in 2004, and 0.95 in 2008.

Conclusions Although the average (mean or median) of smoking prevalence by school decreased, the between-school differences have increased. This suggests that expansion of social inequalities in adolescent health may be occurring

\section{P1-486 PREOPERATIVE BODY MASS AND RISK OF COMPLICATIONS AFTER HYSTERECTOMY ON BENIGN INDICATIONS}

doi:10.1136/jech.2011.142976g.75

${ }^{1} \mathrm{M}$ Osler, ${ }^{*}{ }^{1,2} \mathrm{~S}$ Daugbjerg, ${ }^{1} \mathrm{~B}$ Frederiksen, ${ }^{2} \mathrm{~B}$ Ottesen. ${ }^{1}$ Research Center for Prevention and Health, Copenhagen, Glostup, Denmark; ${ }^{2}$ Department of Gynaecology, Righospitalet, Copenhagen, Denmark

Introduction This study examines preoperative Body Mass Index (BMI) in relation to risk of complications after hysterectomy on benign indications, and explores whether any associations vary by route of surgery.

Methods A cohort study which includes data on health and lifestyle collected prospectively by the surgeon whenever a woman was referred for hysterectomy on a benign indication in Denmark from 2004 to 2009. Logistic regression was used to investigate associations of BMI with complications reported at surgery or during the first 30 days postoperative.

Results Of the 20353 women with complete data, $6.0 \%$ had a BMI $<20 \mathrm{~kg} / \mathrm{m}^{2}, 31.9 \%$ with BMI between 25 and $30 \mathrm{~kg} / \mathrm{m}^{2}$, were classified as overweight and $17.5 \%$ as obese with a BMI $\geq 30 \mathrm{~kg} / \mathrm{m}^{2}$. The rate of complications was $17.6 \%$ with bleeding being the most common specific complication (6.8\%). After adjustment for age, ethnicity, education, smoking, indication for surgery, uterus weight, ASA-classification, co-morbidity status, and route of hysterectomy, obesity was associated with increased risk of bleeding $(\mathrm{OR}=1.27$ $(1.08-1.48))$ and infections $(\mathrm{OR}=1.47(1.23-1.77)$. The risks of bleeding $(\mathrm{OR}=1.48(1.28-1.82))$ and re-operation $(\mathrm{OR}=1.67$ $(1.28-2.17))$ were also increased among women with a $\mathrm{BMI}<20$ The U-shaped relation between BMI and bleeding, and between high BMI and infections were only seen for the abdominal route. The risk of infections was elevated among women with BMI $<20$ who underwent laparoscopic surgery.

Conclusion Obesity increases the risks of bleeding and infections after abdominal hysterectomy. A BMI below 20 seems to increase the risks of bleeding and infection after abdominal and laparoscopic hysterectomy, respectively.

\section{P1-487 COMBINED INFLUENCE OF PHYSICAL ACTIVITY AND HIP CIRCUMFERENCE ON ALL-CAUSE MORTALITY}

doi:10.1136/jech.2011.142976g.76

\begin{abstract}
${ }^{1,2} \mathrm{~J}$ Østergaard, ${ }^{3} \mathrm{M}$ Grønbæk, ${ }^{4} \mathrm{~L}$ Ângquist, ${ }^{5} \mathrm{P}$ Schnohr, ${ }^{4} \mathrm{~T}$ Sørensen, ${ }^{4} \mathrm{~B}$ Heitmann. ${ }^{1}$ Department of Cardiology, Center for Cardiovascular Research, Aalborg Hospital, Aarhus University Hospital, Aalborg, Denmark; ${ }^{2}$ Department of Epidemiology, School of Public Health, Aarhus University, Aarhus, Denmark; ${ }^{3}$ National Institute of Public Health, University of Southern Denmark, Copenhagen, Denmark; ${ }^{4}$ Institute of Preventive Medicine, Copenhagen University Hospitals, Copenhagen, Denmark; ${ }^{5}$ The Copenhagen City Heart Study, Epidemiological Research Unit, Bispebjerg University Hospital, Copenhagen, Denmark
\end{abstract}

Introduction Hip circumference has been shown to be inversely associated with mortality. Reduced femoral fat or muscle atrophy in the gluteofemoral region in those with narrow hips has been proposed as explanations and thus, physical activity is likely to play an important role. The aim was to estimate the combined effects of 